signals for patients with peripheral hearing losses, particularly those using filtering and frequency-specific compression, or dichatic presentation of electronically separated formants (W. A. Ainsworth, Keele University). Preliminary results were encouraging, but it is too early to predict the practical outcome for the deaf. Attempts to provide the profoundly deaf with speech information through visual and tactile inputs have proved disappointing, although it is possible to introduce prosodic information such as intonation (important for interpreting the meaning of speech signals) successfully through a multi-channel vibrator prosthesis (A. Risberg, Stockholm University). The restrictions on the rate of information processing presented by the relativéiy low temporal resolution of the skin and retina indicate that electrical stimulation of the auditory system, for example, by cochlear prostheses, may offer the most likely chance of useful rehabilitation of the profoundly deaf not helped by hearing aids. Present work with single electrode cochlear prostheses is encouraging, particularly for imparting prosodic information, such as the fundamental frequency of speech as indicated by A. J. Fourcin (University College, London). In this way, it ought also to be possible to signal specific speech features such as the "voiced-voiceless" distinction. Both of these should constitute an invaluable aid to lip-reading. However, the full range of speech features required for complete intelligibility can probably only be imparted by multi-electrode stimulation with adequate electrical isolation of the electrodes. This does not seem to be realisable in the foreseeable future.

\section{Honey in the tropics}

\section{from a Correspondent}

The First Conference on Apiculture in Tropical Climates, was held in London on October 18-20. It was arranged by the International Bee Research Association, in conjuction with the journal World Crops. The Conference ended by framing 23 resolutions for submission to international and governmental agencies. A copy is available from the International Bee Research Association (Hill House, Gerrards Cross, Bucks SL9 0NR), together with details of the published proceedings of the Conference. A Second Conference on Apiculture in Tropical Climates is proposed for 1979 or earlier, if possible in the tropics.

The programme at this first conference ranged over topics as diverse as the chemical nature of bee sex pheromones and the state of development of beekeeping in Ethiopia. Tropical countries that want to increase their honey production are understandably tempted to import exotic races, strains, subspecies or species of honeybee that reputedly store honey faster and in larger amounts, but several speakers emphasised the difficulties, and indeed the dangers, of doing this. The aftermath of the 1956 importation of a few queens of the tropical African honeybee A pis mellifera adansonii into South America is common knowledge.

The European honeybee Apis mellifera, an excellent honey producer in many temperate parts of the world, has now been imported into various countries of tropical Asia where the native Apis cerana is not very productive. Some of the importations have been inexplicably disappointing. Soekiman Atmosoedaryo reported on a recent introduction of Apis mellifera into Indonesia by the Forest State Corporation, of which he is Director. Colonies had dwindled away and died, in a way that was only too familiar to other Conference delegates. Possible reasons include the lack of adaptation of Apis mellifera to the many natural enemies of honeybees in the tropicsincluding other insects, and birds and mites. Also this temperate-zone bee follows a diurnal foraging pattern that is ill adapted to tropical plants presenting their nectar and pollen only in early morning and late afternoon.

N. Koeniger (University of Frankfurt, Germany) reported research that throws light on another difficulty experienced by imported species-that of mating. Queens and drones of any Apis species fly during a specific period of the day. If one A pis species is introduced into the territory of another, whose queens and drones fly during a period overlapping that of the imported species, the imported queens are unlikely to mate. Local queens, which are far more numerous, produce the same sex attractant as imported queens, 9-oxodecenoic acid, so drones of both species chase them, but only the local drones can mate with them. Most of the drones chasing an imported queen will also be of the local species; they cannot mate with her even if they locate her, but they keep away imported drones which could mate.

Apis mellifera and Apis cerana are not known to coexist in nature; if they do so, it would seem likely that their mating flight periods have become differentiated, as Koeniger found with the three Apis species present in Sri Lanka.

The management of bees for honey and wax production poses very

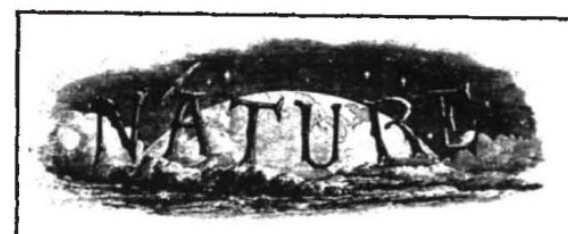

\section{A hundred years ago}

The directors of the Swedish Government railways have turned their special attention to the frequent occurrence of colour-blindness amongst their enginedrivers and other officials. Prof. Holmgren has lately examined the whole staff of the Upsala-Gefle Railway, and amongst the 266 persons examined has found no less than eighteen who suffered from this defect, and who therefore were utterly useless and unfit for railway service.

A very fine new university building has been erected at Kiel, one marked peculiarity of which is that it has no "carcer", or prison, which hitherto, it seems, has been an invariable appendage to German universities.

From Nature, 15, November 30, 110; 1876.

different problems in tropical and in temperate climates. Most of the early studies on bees were made in temperate regions, and perhaps for this reason, bee behaviour there has often been regarded as normal, and behaviour in the tropics as aberrant; yet it may well be the other way round. When the food resources of an area fail, tropical honeybees commonly migrate to an area where forage exists, as entire colonies, leaving their established nests (T. M. Chandler, International Development Research Centre, Nairobi). As a means of survival this migration is an alternative to the massive food hoarding of honeybees which have to survive a winter dearth period.

Jim Nightingale (Sasumua Estates, Njoro, Kenya) has lived with bees in Kenya for 54 years, and he was able to describe bees' migration routes in earlier days when human use of land was sparse and primitive: to-and-fro movements between the highlands and the floor of the Rift Valley--between the Aberdare Mountains and Naivasha, between the Mau forests and the Valley, and between the Kipsigis areas and down towards Lake Victoria. The human population has now upset ageold patterns in Kenya, but Ethiopia is not yet changed. Mammo Gebreyesus (PO Box 30407, Addis Abaha) maintains apiaries in the highlands, and in the Rift Valley $55 \mathrm{~km}$ to the east and $1,500 \mathrm{~m}$ lower down. He achieves continuous honey production by moving his hives between the two apiaries at the migration periods, so that the colonies do not leave them.

Mammo Gebreyesus is one of Ethiopia's very few modern beekeepers: 